\title{
The Efficacy of Pair Interaction in Teaching Communicative English Grammar
}

\author{
Suhartina R \\ Stkip-Yapim Maros, Indonesia
}

\begin{abstract}
Grammar learning for proficiency has been debated by the language acquisition and linguists proponents. The study aimed at finding out the best grammar teaching strategies for proficiency to be used in actual communication. The study used a quasi-experimental non-equivalent control group design that involved 120 students of English Department of four different private universities in Makassar which were selected randomly from the same year intake. The data were collected through proficiency test which covered the aspects of grammar, listening, speaking, reading and writing. Multivariate analysis was used to examine the proficiency differences among students who learned grammar through pair interaction and those learned through small groups interaction in five areas of proficiency. The data analysis results and interpretation showed that students who learned grammar through pair interaction activities outperformed their peers in small groups interaction to a large extent in all areas of language proficiency. Pair-Interaction activities can be used extensively for low proficiency students in tertiary education as it provides more opportunities for students to practice accross the scheduled communicative grammar activities.
\end{abstract}

Index Terms - pair interaction, grammar teaching, communicative activities, language proficiency

\section{INTRODUCTION}

Controversy over the needs to teach grammar seems to be disconnected from the view point conflict of language acquisition in one hand and language learning on the other that leads to proficiency and mastery of language knowledge. Those who reject the teaching of grammar assume that grammar should not be taught because it can be obtained naturally. Conversely, those who support the teaching of grammar assume that grammar should be taught regularly and systematically to assist the acquisition of the grammatical structure of the language being learned. Without analyzing the fact that grammar can be acquired both naturally and nurturally, the researchers argue that the teaching of formal grammar is still needed, especially in countries that use English as a foreign language, Ellis (2006), Setiono (2004), Hinkel and Fotos (2002), Dardjowidjojo (2000), and Sadtono (1992).

In line with the above notions, the researcher interviewed several English Grammar lecturers at some private universities in Makassar. From the interviews, it was infered that teaching English grammar could become the very basic priority especially if the objective is written communication, more specifically in term of scientific written communication. On the other hand, if the objective to achieve is oral communication oriented, then the teaching of grammar seems to become uncategorized priority. Lado's notion $(1988,79)$ says "a person who knows the meaning of all the words of an utterance but none of its grammar will understand most of the message, whereas another who knows all of the grammar and none of the words will understand very little if anything" seems influential profoundly to the communication oriented proponents.

Some English grammar lecturers at several private universities in Makassar admitted that students' English proficiencies were varied from basic to intermediate levels. The teaching of English grammar in English Department of the private universities was still with conventional pattern prescribing structural models and generally separated from the teaching of the four language skills. As a result, such teaching model led to the understanding of language structure with major flaws in the aspects of auro-oral proficiency. Hence, the teaching of grammar should be done with a variety of interesting teaching techniques to help students understand and process their metalinguistic understanding as a first step towards internalizing the use of grammar (Ellis, 2006; Hedge, 2000; and Ur, 1996). The fundamental question arising then is the need of teaching grammar and strategies in teaching it to students that is believed can optimize the ability of students to understand and to use the grammar in actual communication both for oral and written instead.

In line with the context explained above, the teaching of grammar using communicative approach can be done by using purposeful interaction models and its prevalence is very strong in student proficiency training using grammatical aspects of the practice of communicating. Interaction in the classroom as suggested by Vygotsky (1978) and Bandura (1977) is central on learning to socialize. Interactions performed by students in the classroom with anyone or anything should give them the opportunity to explore ideas, interpret, and react to opposing ideas, and a variety of other communication skills. Students who engage in open dialogue with other participants will have the opportunity to use the language learned by exploration and interpretation of each of these ideas. Therefore, in planning the interactions it is very important to consider the tasks that can be done and learned by the students. If the tasks can be understood and accepted as social activities, the activities within interactions will be considered as the objectives that should be targeted. 
Moreover, the students' learning experiences in a social interaction classroom will be actualized within social contexts outside the classrooms that will lead to strengthening the purpose of interactions acted out by the students and other possible values offered by the interaction models, either pair or small groups ( $3-5$ participants).

In the context of pair interaction implementation students are requested not only to proficiently use grammatical English in communicating their ideas and notions to others during lecturing session, but also oblige them to use grammatical English when talking or interacting with others in discussing lecturing activities as well as when talking about the grammaticality of the language grammar being learned. In other words, students are habituated to use the English language grammatically for both written and oral communication in every lecturing activities. Hence, the habituating process will automatically bring about positive effects in their daily communication activities beyond lecturing process.

Some studies showed that the teaching of grammar with pair interaction model, for example, in a collaborative manner significantly affected the achievement of language performance, Watanabe and Swain (2007). Pair interactions also contributed positively to the proficiency and language competence, Yassi (2009), and generated joint construction (joint development) in terms of morphological knowledge, Baleghizadeh (2010). In addition, pair interactions also proved to be feasible and practical for use as a method of teaching grammar in a communicative teaching, Hanafiah (2011). To verify the findings above, the researcher concluded that there must be a specific research focusing mostly on the implementation of pair interactions and their higher strengths compared with other models of small group interactions through which this study was based on, entitling "The Efficacy of Pair Interaction in Teaching Communicative English Grammar".

The main objective of this study was to improve students' proficiency in using grammatical English both for written and oral communication with pair interactions as the main model of learning. Students' achievement gained through this learning model was compared with other models of small group interactions. Therefore, this study aimed at finding out teaching English grammar strategies that can be used in actual communication for excellent proficiency.

\section{THEORETICAL CONSIDERATION}

The advantages of pair interaction have been proven by many researchers, among others were Storch (2002), Noni (2003), Watanabe and Swain (2007), Yassi (2009), Baleghizadeh (2010), Tan, Wigglesworth and Storch (2010), and Hanafiah (2011).

Storch (2002) investigated the performance of three pairs of adult ESL students on a writing task assigned in class. The main source of data was the transcripts of their pair talk. Other sources of data included the researcher's observation notes and the written text the pairs produced. Data were analyzed for main features of student interactions and characteristics of collaborative pair work were identified. The results showed that students working in pairs may not necessarily work in a collaborative manner, but where they do collaborate this may have an effect on task performance. In 2007, Storch investigated the merits of pair work by comparing pair and individual work on an editing task and by analyzing the nature of pair interaction. The study was conducted in four intact ESL tertiary classes. Students in class A completed the task in pairs and in class B individually. In classes $\mathrm{C}$ and D students were given the choice of completing the task in pairs or individually. In class $A$ all pair talk was audio recorded. Analysis of the edited texts showed that there were no significant differences between the accuracy of tasks completed individually and those completed in pairs. Analysis of the transcribed pair talk showed that most pairs engaged actively in deliberations over language and tended to reach correct resolutions. Thus the results suggest that although pair work on a grammar-focused task may not lead to greater accuracy in completing the task, pair work provides learners with opportunities to use the second language for a range of functions, and in turn for language learning.

In collaboration with Tan and Wigglesworth, Storch (2010) investigated the effect of the medium of communication on the nature of pair interaction. The study involved six pairs of beginner participants in a Chinese class completing seven different tasks. Each task was completed twice, once in face to face (FTF), and another via computer mediated communication (CMC). All pair talk was audio recorded, and on-line communication was logged. Using Storch's (2002) model of patterns of pair interaction, five patterns were identified: collaborative, cooperative, dominant/dominant, dominant/passive and expert/novice. The medium of communication was found to affect the pattern of interaction. In CMC some pairs became more collaborative, or cooperative.

The three different pieces of research done by Storch $(2002,2007$, and 2010) and her colleagues favored the use of pair interactions in certain paces of tasks and activities in language classrooms. What so interesting about Storch's studies were the contributions of tasks or activities assigned to students working in pair on patterns of interactions which in turn affect the ways students' language learning. Thus, it is worthy to apply Storch's model of patterns of pair interaction in this research as another perspective to finding the effects on the students' grammar learning.

Noni's research (2003) focusing on face to face teaching and Computer-Assisted Language Learning (CALL) in ELT based on individual preference reported that face to face interactions were found to be more effective in improving students' achievement than CALL. It implied that real interactions among students and teacher in classroom setting were richer and more meaningful than virtual interactions on computer.

Collaborative research done by Watanabe and Swain (2007) investigated the effects of second language (L2) proficiency differences in pairs and patterns of interaction on L2 learning, making use of both qualitative and 
quantitative data. They designed the study in such a way that four different core participants interacted with higher and lower proficiency non-core participants. These learners engaged in a three-stage task involving pair writing, pair comparison (between their original text and a reformulated version of it) and individual writing. The core participants also engaged in a stimulated recall after the task. They analyzed each pair's collaborative dialogue in terms of languagerelated episodes and patterns of pair interaction as well as each learner's individual post-test score. The findings suggested that the patterns of pair interaction greatly influenced the frequency of LREs and post-test performance. When the learners engaged in collaborative patterns of interaction, they were more likely to achieve higher posttest scores regardless of their partner's proficiency level. It seems that proficiency differences do not necessarily affect the nature of peer assistance and L2 learning. Thus, the merit of this research that can be used as a perspective towards this current research is the nature of interactions where students learn hand in hand to solve their problem.

Yassi's research (2009) focusing on a model of grammar learning for proficiency using paired interaction at the Faculty of Letters of Hasanuddin University reported that it was evident for paired interaction contributed significantly to the improvement of students' proficiency in using grammar as well as students' competence in using the four language skills. The findings of Yassi's research implied that through paired interaction, tertiary English language learners could achieve better accuracy in performing their language skills competence.

Baleghizadeh (2010) carried out a study focusing on the investigation of the effect of pair work on a word-building task in two EFL classes. In the study, there were forty Iranian adult students participated. The participants in the experimental group completed the word-building task in pairs following the Think-Pair-Share technique, whereas the participants in the control group did the same task individually. Results of the data analysis showed that the participants in the experimental group achieved significantly higher scores on the given task than the participants in the control group. This fact indicates that the students' joint efforts while collaborating with each other are likely to result in coconstruction of morphological knowledge.

The research done by Hanafiah (2011) was basically the verification of Yassi's study. Hanafiah used similar approach in teaching English grammar at Faculty of Teacher Training and Education of UNIDAYAN Baubau, Southeast Sulawesi. Hanafiah concluded that teaching English grammar through 'Learner - Learner Interaction' (LLI) in the pair activities model is a feasible and practical teaching method that puts English grammar into a communicative approach or into action. One of the implications of Hanafiah's research findings is to offer practicality of pair activities model as a teaching strategy when English grammar is intended to be the atmosphere of proper communication.

Two collaborative studies done by Yassi (2009) and continued by Hanafiah (2011) were taking place at EFL tertiary education in Eastern Indonesian setting to investigate the effects of pair work model in teaching grammar for proficiency. Both studies involved single university and contributed to the development of grammar teaching using pair work activities. This current study was quite similar to these two studies but unique in terms of the use of various kinds of grouping students into pair, small groups of three, four and five in four different universities. Apart from Yassi's (2009) and Hanafiah's (2011), the other studies listed and described above were concluded to support the use of pair interaction in teaching English in classroom setting but the majority of them was in ESL setting. Besides, the studies did not clarify the specific target of language elements except the one carried out by Storch (2007) which was designed to use pair work on a grammar-focused task for accuracy. Thus, it was pertinent for the current research to use the previous research findings to help develop the concepts of pair work activities in teaching grammar to achieve proficiency.

\section{METHODOLOGY}

\section{a. Location and Research Plan}

This research was carried out at four different private universities within Kopertis Wilayah IX Sulawesi in Makassar. The purpose of the present study was to obtain a deeper understanding of the effects of classroom interaction strategies in English grammar teaching for proficiency at private tertiary education. The quantitative focus concerned a comprehensive assessment of the English proficiency of the participants in grammar, listening, speaking, reading and writing through varied classroom interaction activities. Thus, a comparative research with respect to quantitative paradigm was used as the research design.

\section{b. Population and Sample}

The population of this research was the freshmen students of English Education Department and English Literature at four different private universities in Makassar. The sample selected from the population were 122 (reduced to 120 for the analysis interest) and each of the sample was selected purposively using the assumptions that the majority of them were still genuinely interested in what the study was about and would take the participation seriously. Besides, they had not received a lot of grammatical input through communicative language activities. Thus, progress that may be achieved in learning during the research could be clearly detected. The selection of the sample was not randomized as the structure of the class should be maintained as it was. Besides, there was no specific reason of assigning certain university into any models of grouping and it was randomly assigned as it is assumed that they relatively have similar ability as seen in their pretest scores (UMI 45.35, STKIP-YPUP 41.68, Universitas 45 43.74, and UNISMUH 46.96).

c. Data Collection Procedures 
In general, the data collection was done in three phases: (1) Pre-Intervention; (2) Intervention; and (3) PostIntervention. In the pre-intervention, the researcher piloted the grammar test to 30 students at the English Education Department of UIN Alauddin Makassar, located the target participants at four different campuses (UMI, YPUP, 45 and UNISMUH), set them into four different treatments, and administered the pretests to the whole participants. In the intervention phase, the researcher applied four types of organizing or grouping students in learning grammar for proficiency in communicative or interactive situations. The treatment for the first group (G2) was 'Pair-Interaction activities' and hence became the experimental group. The group was assigned to have a maximum opportunity to use grammatical points in oral and written communication in pair work activities. It was assumed that the smaller the number of students involved in communication, the more intense and much more opportunity for them to practice. Thus, practicing in paired interaction was assumed to be more potential to increase the amount of practicing time opening the way of achieving proficiency. As for the control groups, the second group (G3) was treated by 'Group-Interaction activities of 3' (composing 10 small groups), the third group (G4) by 'Group-Interaction activities of 4' (composing 8 small groups), and the fourth group (G5) by 'Group-Interaction activities of 5' (composing 6 small groups). All the treatment and procedures for the control groups were similar to those in the experimental group including the core materials. The differences were dealing with the grouping, the material design, and the practicing time for individuals. It was assumed that the larger the number of student involved in communication, the less intense and the less opportunity for them to practice. Thus, practicing in a larger group interaction was assumed to decrease the amount of practicing time. In the Post-Intervention phase, the researcher used a set of test to the whole participants in four different campuses. To avoid bias in assessing the speaking and writing productions, the researcher involved three inter-raters to do the assessment. The assessment results from grammar expressions test, listening test, speaking test, reading test, and writing test, were used as the primary data in this research.

\section{RESEARCH FINDINGS}

\section{a. Univariate Anova}

The mean score of English proficiency of the students who learned grammar through Pair-Interaction activities (G2) before the intervention was 45.35 and increased to 57.88 after the intervention. The areas of linguistics and communication in which the English proficiency increased to a large extent were grammar expressions from 43.01 to 69.03 and speaking from 55.53 to 80.16. A slight increase occurred in the areas of listening (35.11 to 42.11) and writing (43.11 to 47.56); but tended to level off at reading comprehension (50.00 to 50.56). The following histogram figured out the above data more clearly and comprehensively through which it was concludable that students' achievement improved in all English skills being taught under the model of Pair-Interaction activities.

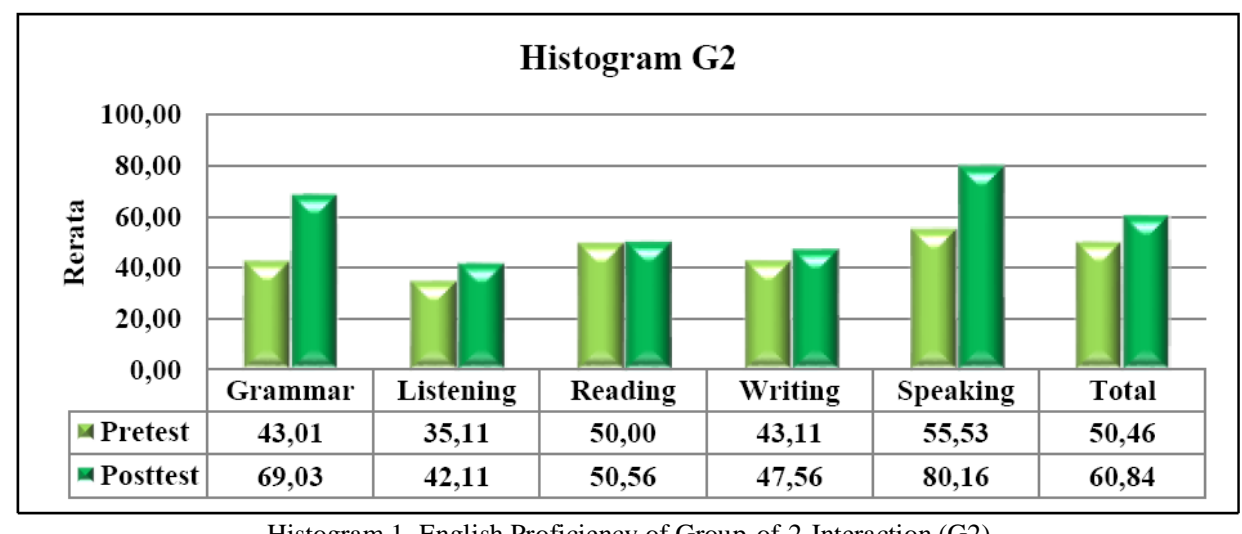

Histogram 1. English Proficiency of Group-of-2-Interaction (G2)

The mean score of English proficiency pretest of the students who learned grammar through Group-of-3-Interaction activities (G3) was 41.67 and increased to 47.61 after the intervention. The areas of linguistics and communication in which the English proficiency increased to a large extent was reading from 36.67 to 50.28. A slight increase occurred in other areas; grammar expressions (42.90 to 50.86) and writing (46.51 to 51.00); but tended to level off at listening comprehension (29.78 to 32.33 ) and speaking (52.53 to 53.58). To see more clearly the students' proficiency after the implementation of Group-of-3-Interaction (G3) model, the following histogram might be of helpful reference, through which it was concludable that all skills being taught under the implementation of the G3 model underwent from adequate to significant improvement. 


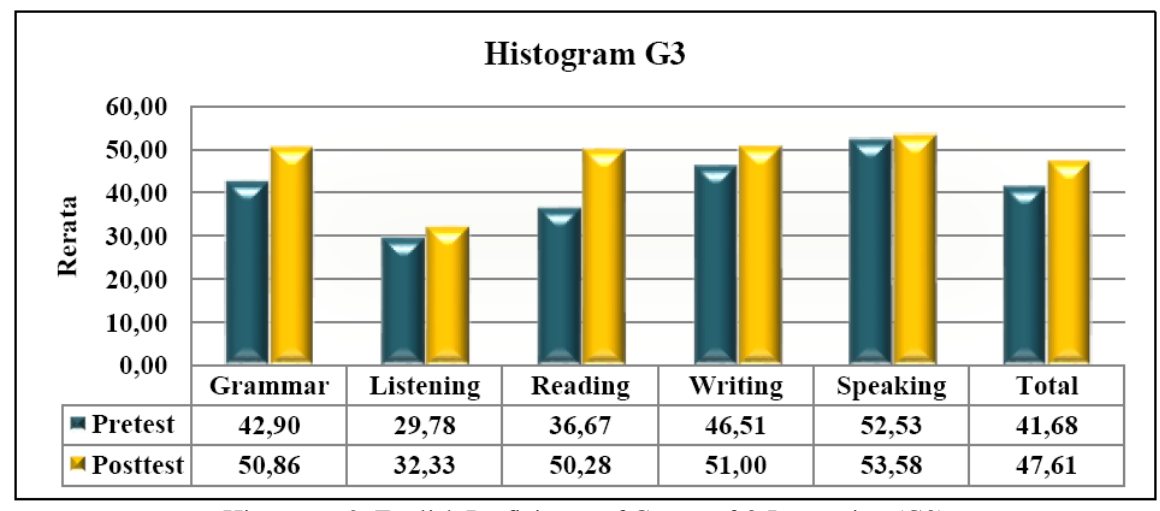

Histogram 2. English Proficiency of Group-of-3-Interaction (G3)

The mean score of English proficiency pretest of the students learning through Group-of-4-Interaction activities (G4) was 43.73 and increased to 48.21 after the intervention. The linguistic and communication areas in which the English proficiency increased significantly were reading from 48.96 to 57.81 and speaking from 47.33 to 56.48 . A minor increase occurred in case of listening, that is from 33.33 to 36.46. Grammar and writing tended to level off at similar scores. The following histogram would release more comprehensively the students' proficency improvement through the use of G5 learning model. The data in the histogram showed that although not as significant as that reached through the use of G2 model, all skills being taught under the implementation of G5 model underwent improvement.

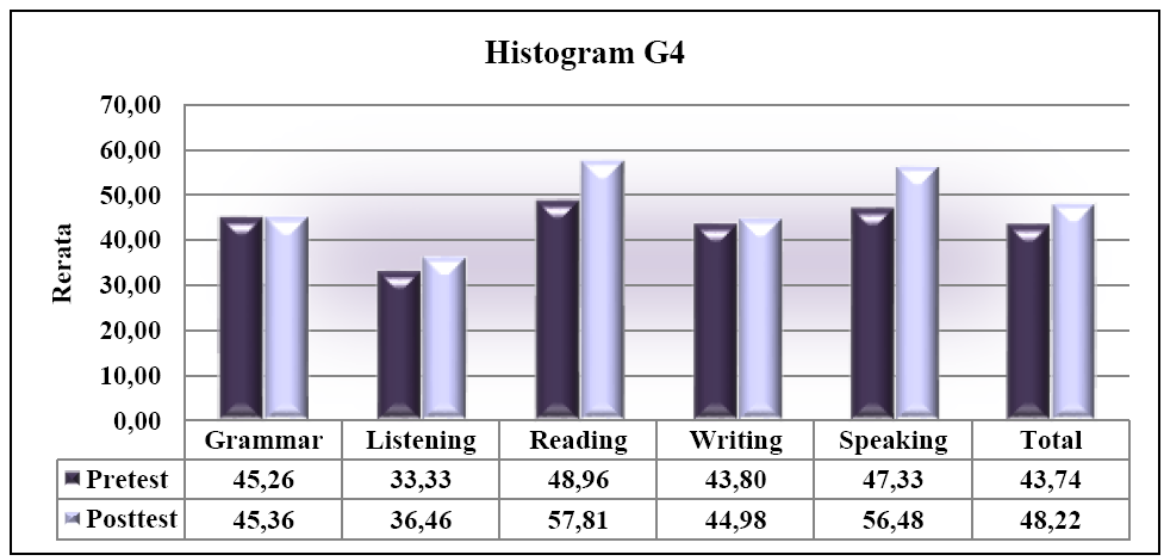

Histogram 3. English Proficiency of Group-of-4-Interaction (G4)

In case of Group-of-5-Interaction (G5) implementation in learning English Grammar, the mean score of English proficiency pretest of the students was 46.96 and increased to 49.52 after the intervention. The linguistic and communication areas in which the English proficiency increased significantly were speaking from 57.49 to 68.87 and grammar expressions from 41.72 to 46.24 . A minor increase occurred in case of writing that is from 43.71 to 46.31 . Listening tended to level off at similar scores. Unfortunately because in case of reading area, the students' learning achievement underwent significant decrease, namely from 52.78 to 46.11 . The following histogram could be of helpful data presentation to see the effect of interactive learning models especially in case of learning English grammar.

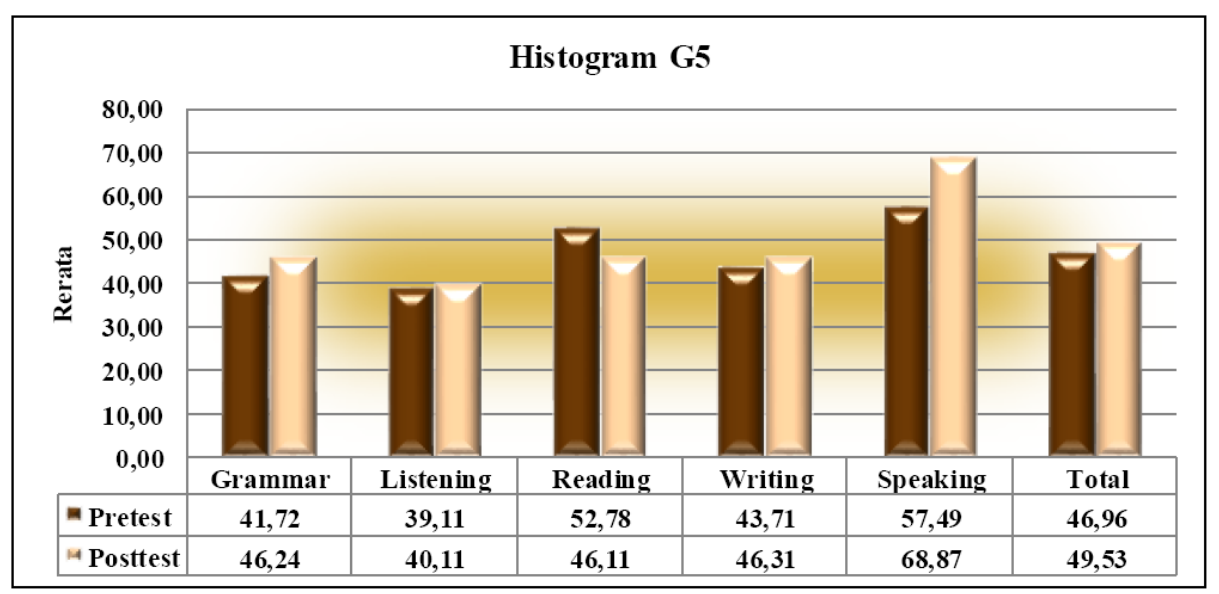

Histogram 4. English Proficiency of Group-of-5-Interaction (G5) 


\section{b. Hypothesis Testing}

\section{1) ANOVA Test}

For one-factor ANOVA, the $F_{\text {score }}$ for the four groups (G2, G3, G4 and G5) is 7.537 with the probability (p) 0.000 . As the probability is smaller than $\alpha 0.05(0.000<0.05)$, the null hypothesis $\left(\mathrm{H}_{\mathrm{o}}\right)$ is rejected or the mean scores of the four groups are significantly different. Besides, the $F_{\text {score }}$ for the two tests (Posttest and Pretest) is 32.130 with the probability (p) 0.000. As the probability is smaller than $\alpha 0.05(0.000<0.05)$, the null hypothesis $\left(\mathrm{H}_{\mathrm{o}}\right)$ is rejected or the mean scores of the two tests are significantly different. For two-factor ANOVA, the $F_{\text {score }}$ for the interaction between group and test is 3.773 with the probability $(p) 0.011$. As the probability is smaller than $\alpha 0.05(0.011<0.05)$, the null hypothesis $\left(\mathrm{H}_{\mathrm{o}}\right)$ is rejected or there is an interaction between the four groups and the two tests used. The above data showed that different model of interaction in learning English grammar brought about different students' learning achievement in which Pair Interaction Model seemed to be the most appropriate to be regularly implemented rather than other threes. The following was the summary table of the anova test above.

TABLE 1.

SUMMARY TABLE OF THE ANOVA TEST

Dependent Variable:MeanScores

\begin{tabular}{llllll}
\hline Source & Type III Sum of Squares & df & Mean Square & F & Sig. \\
\hline Corrected Model & $4962.691^{\mathrm{a}}$ & 7 & 708.956 & 9.437 & .000 \\
Intercept & 543608.198 & 1 & 543608.198 & 7235.881 & .000 \\
Group & 1698.580 & 3 & 566.193 & 7.537 & .000 \\
Test & 2413.829 & 1 & 2413.829 & 32.130 & .000 \\
Group * Test & 850.282 & 3 & 283.427 & 3.773 & .011 \\
Error & 17429.406 & 232 & 75.127 & & \\
Total & 566000.296 & 240 & & & \\
Corrected Total & 22392.098 & 239 & & & \\
\hline
\end{tabular}

a. R Squared $=.222$ (Adjusted R Squared $=.198)$

As found that there was a significant difference among the four groups' mean scores, it is important to know which groups' paired mean scores are significantly different through Tukey test. The summary results of Post Hoc Test using Tukey test analysis following the ANOVA test shows the mean difference between the posttest and pretest of G2 is 12.5280. At the $95 \%$ confidence interval, the mean scores range from 5.6825 to 19.3735 . The significance test of the mean difference between the posttest and pretest of G2 is based on probability level $(p)$ in Sig. column. If the probability is bigger than $0.05(\mathrm{p}>0.05)$, the $\mathrm{H}_{\mathrm{o}}$ is accepted and if the probability is smaller than $0.05(\mathrm{p}<0.05)$, the $\mathrm{H}_{\mathrm{o}}$ is rejected. This significance test is effective for all groups compared. The Tukey test $(\mathrm{Q})$ results from the interaction of groups' mean scores that significantly different is $\mathrm{Q}_{1}(0.000<0.05)$. Therefore, the analysis is continued to test the hypotheses. The summary data can be seen in the following table.

TABLE 2.

POST HOC - TUKEy TEST RESUlt SUMMARY TABLE

Multiple Comparisons

Post_Pre MeanScore Tukey HSD

\begin{tabular}{lllllll}
\hline \multirow{2}{*}{ (I) Test } & (J) Test & $\begin{array}{l}\text { Mean Difference } \\
\text { (I-J) }\end{array}$ & Std. Error & Sig. & \multicolumn{2}{c}{ 95\% Confidence Interval } \\
\cline { 5 - 7 } PostG2 & PreG2 & $12.5280^{*}$ & 2.23796 & .000 & 5.6825 & 19.3735 \\
PostG3 & PreG3 & 5.9323 & 2.23796 & .144 & -.9132 & 12.7778 \\
PostG4 & PreG4 & 4.3457 & 2.23796 & .524 & -2.4998 & 11.1912 \\
PostG5 & PreG5 & 2.5650 & 2.23796 & .946 & -4.2805 & 9.4105 \\
\hline
\end{tabular}

Based on observed means.

The error term is Mean Square(Error) $=75,127$.

$*$. The mean difference is significant at the ,05 level.

For G2 (Pair-Interaction), the mean score is 57.88 with the minimum score of 39.23 and the maximum is 74.68 . With the significance level of $95 \%$, the average score is in the range of 54.50 to 61.25 . For G3 (Group-3-Interaction), the mean score is 47.61 with the minimum score of 33.05 and the maximum is 71.86 . With the significance level of $95 \%$, the average score is in the range of 44.44 to 50.77 . For G4 (Group-4-Interaction), the mean score is 48.03 with the minimum score of 33.54 and the maximum is 68.55 . With the significance level of $95 \%$, the average score is in the range of 45.01 to 51.05. For G5 (Group-5-Interaction), the mean score is 49.52 with the minimum score of 30.12 and the maximum is 76.71. With the significance level of $95 \%$, the average score is in the range of 45.17 to 53.88 . For all groups, the mean score is 50.76 with the minimum score of 30.12 and the maximum is 76.71 . With the significance level of $95 \%$, the average score is in the range of 48.92 to 52.60 .

The ANOVA (F test) of the four groups' mean scores shows that the $F_{\text {score }}$ is 7.841 and the $F_{\text {table }}$ is 2.685 at df $3 ; 116$ $(7.841>2.685)$. Since the $F_{\text {score }}$ is larger than the $F_{\text {table }}$, it is concluded that the research rejects the null hypothesis and accepts the alternative hypothesis. It means that the mean scores of all groups are significantly different. The Tukey test (Q) results from the interaction of groups' mean scores that significantly different are Q1 $(0.000<0.05)$, Q2 $(0.001<$ $0.05)$ and Q3 $(0.005<0.05)$. Therefore, the analysis is continued to test the hypotheses. 
For the area of English proficiency in which the students who learned grammar through Pair-Interaction activities outweigh their peers in Group-Interaction activities can be seen in the summary of some significant results of the Tukey tests (Q) in Tables 3 and 4 below.

TABLE 3.

TUKEY TEST

Multiple Comparisons Dependent Variable:Posttest_Score

\begin{tabular}{|c|c|c|c|c|c|c|c|}
\hline & \multirow{2}{*}{ (I) Group } & \multirow{2}{*}{ (J) Group } & \multirow{2}{*}{ Mean Difference (I-J) } & \multirow{2}{*}{ Std. Error } & \multirow{2}{*}{ Sig. } & \multicolumn{2}{|c|}{$95 \%$ Confidence Interval } \\
\hline & & & & & & Lower Bound & Upper Bound \\
\hline \multirow[t]{12}{*}{ Tukey HSD } & G2 & G3 & $10.27100^{*}$ & 2.43221 & .000 & 3.9310 & 16.6110 \\
\hline & & G4 & $9.84567^{*}$ & 2.43221 & .001 & 3.5057 & 16.1856 \\
\hline & & G5 & $8.35367^{*}$ & 2.43221 & .005 & 2.0137 & 14.6936 \\
\hline & G3 & G2 & $-10.27100^{*}$ & 2.43221 & .000 & -16.6110 & -3.9310 \\
\hline & & G4 & -.42533 & 2.43221 & .998 & -6.7653 & 5.9146 \\
\hline & & G5 & -1.91733 & 2.43221 & .860 & -8.2573 & 4.4226 \\
\hline & G4 & G2 & $-9.84567^{*}$ & 2.43221 & .001 & -16.1856 & -3.5057 \\
\hline & & G3 & .42533 & 2.43221 & .998 & -5.9146 & 6.7653 \\
\hline & & G5 & -1.49200 & 2.43221 & .928 & -7.8320 & 4.8480 \\
\hline & G5 & G2 & $-8.35367^{*}$ & 2.43221 & .005 & -14.6936 & -2.0137 \\
\hline & & G3 & 1.91733 & 2.43221 & .860 & -4.4226 & 8.2573 \\
\hline & & G4 & 1.49200 & 2.43221 & .928 & -4.8480 & 7.8320 \\
\hline
\end{tabular}

*. The mean difference is significant at the 0.05 level.

TABLE 4.

SUMMARY OF TUKEY TEST RESULT

\begin{tabular}{lllll}
\hline Paired Group & $\boldsymbol{p}$ & $\boldsymbol{\alpha}$ & Notation & Conclusion \\
\hline $\mathrm{Q}_{1}(\mathrm{G} 2-\mathrm{G} 3)$ & 0.000 & 0.05 & $0.000<0.05$ & Significant \\
$\mathrm{Q}_{2}(\mathrm{G} 2-\mathrm{G} 4)$ & 0.001 & 0.05 & $0.001<0.05$ & Significant \\
$\mathrm{Q}_{3}(\mathrm{G} 2-\mathrm{G} 5)$ & 0.005 & 0.05 & $0.005<0.05$ & Significant \\
$\mathrm{Q}_{4}(\mathrm{G} 3-\mathrm{G} 4)$ & 0.998 & 0.05 & $0.998>0.05$ & Insignificant \\
$\mathrm{Q}_{5}(\mathrm{G} 3-\mathrm{G} 5)$ & 0.860 & 0.05 & $0.860>0.05$ & Insignificant \\
$\mathrm{Q}_{6}(\mathrm{G} 4-\mathrm{G} 5)$ & 0.928 & 0.05 & $0.928>0.05$ & Insignificant \\
\hline
\end{tabular}

The two tables show that the results from the interaction of areas mean scores that significantly different are: (a) Grammar for G2 and G3 (0.001 < 0.05); (b) Grammar for G2 and G4 (0.000<0.05); (c) Grammar for G2 and G5 $(0.000<0.05)$; (d) Speaking for G2 and G3 (0.000<0.05); (e) Speaking for G2 and G4 $(0.000<0.05)$; and, (f) Speaking for G5 and G3 $(0.014<0.05)$. This means that in case of Grammar, the G2 model of interaction yields in better result rather than that of the other three. In case of speaking, the G2 model of interaction yields in better result than that of G3 and G4 models. On the other hand, the learning achievements yielded through the implementation of G3, G4, and G5 models are insignificant. That is to say, in case of learning English Grammar, the smaller the member of a group interaction model, the better the learning achievement will be. Conversely, the bigger the member of a group interaction model, the worse the learning achievement will be.

2) Hypothesis Test

Hypothesis 1 assumed $\mathrm{H}_{\mathrm{a}}$ which stated that, "There is a difference of English proficiency of the students who learned integrative communicative grammar within Pair-Interaction activities before and after the intervention." The Tukey test shows that the mean difference of the Posttest and Pretest of G2 (Pair-Interaction) is 12.5280 with the probability $(p)=0.000$. Since the probability is smaller than $\alpha 0.05(0.000<0.05)$, the null hypothesis $\left(\mathrm{H}_{\mathrm{o}}\right)$ is rejected which means that there is a significant difference of English proficiency of the students who learned grammar through PairInteraction activities before and after the intervention.

Hypothesis 2 assumed $\mathrm{H}_{\mathrm{a}}$ which stated that, "There is a difference of English proficiency of the students who learned integrative communicative grammar within Group-3-Interaction activities before and after the intervention." The Tukey test shows that the mean difference of the Posttest and Pretest of G3 (Group-3-Interaction) is 5.9323 with the probability $(p)=0.144$. Since the probability is larger than $\alpha 0.05(0.144>0.05)$, the null hypothesis $\left(\mathrm{H}_{\mathrm{o}}\right)$ is accepted which means that there is no significant difference of English proficiency of the students who learned grammar through Group-3-Interaction activities before and after the intervention.

Hypothesis 3 assumed $\mathrm{H}_{\mathrm{a}}$ which stated that, "There is a difference of English proficiency of the students who learned integrative communicative grammar within Group-4-Interaction activities before and after the intervention." The Tukey test shows that the mean difference of the Posttest and Pretest of G4 (Group-4-Interaction) is 4.3457 with the probability $(p)=0.524$. Since the probability is larger than $\alpha 0.05(0.524>0.05)$, the null hypothesis $\left(\mathrm{H}_{\mathrm{o}}\right)$ is accepted which means that there is no significant difference of English proficiency of the students who learned grammar through Group-4-Interaction activities before and after the intervention.

Hypothesis 4 assumed $\mathrm{H}_{\mathrm{a}}$ which stated that, "There is a difference of English proficiency of the students who learned integrative communicative grammar within Group-5-Interaction activities before and after the intervention." The 
Tukey test shows that the mean difference of the Posttest and Pretest of G5 (Group-5-Interaction) is 2.5650 with the probability $(p)=0.946$. Since the probability is larger than $\alpha 0.05(0.946>0.05)$, the null hypothesis $\left(\mathrm{H}_{\mathrm{o}}\right)$ is accepted which means that there is no significant difference of English proficiency of the students who learned grammar through Group-5-Interaction activities before and after the intervention.

Hypothesis 5 assumed $\mathrm{H}_{\mathrm{a}}$ which stated that, "The English proficiency of the students who learned integrative communicative grammar through Pair-Interaction activities will be higher than those learned integrative communicative grammar through Group-3-Interaction activities." The Tukey test results for the paired group compared of $\mathrm{Q}_{1}(\mathrm{G} 2$ and G3) shows that the probability $(p)$ level is 0.000 . As the probability is smaller than $\alpha 0.05(0.000<0.05)$, the null hypothesis $\left(\mathrm{H}_{\mathrm{o}}\right)$ is rejected and concluded that the English proficiency of the students who learned grammar through Pair-Interaction activities is significantly higher than those learned grammar through Group-3-Interaction activities. In other words, learning grammar for proficiency through Pair-Interaction activities will be more effective than learning it through Group-3-Interaction activities.

Hypothesis 6 assumed $\mathrm{H}_{\mathrm{a}}$ which stated that, "The English proficiency of the students who learned integrative communicative grammar through Pair-Interaction activities will be higher than those learned integrative communicative grammar through Group-4-Interaction activities." The Tukey test results for the paired group compared of $\mathrm{Q}_{2}(\mathrm{G} 2$ and G4) shows that the probability $(p)$ level is 0.001 . As the probability is smaller than $\alpha 0.05(0.001<0.05)$, the null hypothesis $\left(\mathrm{H}_{\mathrm{o}}\right)$ is rejected and concluded that the English proficiency of the students who learned grammar through Pair-Interaction activities is significantly higher than those learned grammar through Group-4-Interaction activities. In other words, learning grammar for proficiency through Pair-Interaction activities will be more effective than learning it through Group-4-Interaction activities.

Hypothesis 7 assumed $\mathrm{H}_{\mathrm{a}}$ which stated that, "The English proficiency of the students who learned integrative communicative grammar through Pair-Interaction activities will be higher than those learned integrative communicative grammar through Group-5 Interaction activities." The Tukey test results for the paired group compared of $\mathrm{Q}_{3}(\mathrm{G} 2$ and G5) shows that the probability $(p)$ level is 0.005 . As the probability is smaller than $\alpha 0.05(0.005<0.05)$, the null hypothesis $\left(\mathrm{H}_{\mathrm{o}}\right)$ is rejected and concluded that the English proficiency of the students who learned grammar through Pair-Interaction activities is significantly higher than those learned grammar through Group-5-Interaction activities. In other words, learning grammar for proficiency through Pair-Interaction activities will be more effective than learning it through Group-5-Interaction activities.

Hypothesis 8 assumed $\mathrm{H}_{\mathrm{a}}$ which stated that, "The English proficiency of the students who learned integrative communicative grammar through Group-3-Interaction activities will be higher than those learned integrative communicative grammar through Group-4-Interaction activities." The Tukey test results for the paired group compared of $\mathrm{Q}_{4}(\mathrm{G} 3$ and G4) shows that the probability $(p)$ level is 0.998 . As the probability is larger than $\alpha 0.05(0.998>0.05)$, the null hypothesis $\left(\mathrm{H}_{\mathrm{o}}\right)$ is accepted and concluded that the English proficiency of the students who learned grammar through Group-3-Interaction activities is not significantly higher than those learned grammar through Group-4Interaction activities. In other words, learning grammar for proficiency through Group-3-Interaction activities will not be more effective than learning it through Group-4-Interaction activities.

Hypothesis 9 assumed $\mathrm{H}_{\mathrm{a}}$ which stated that, "The English proficiency of the students who learned integrative communicative grammar through Group-3-Interaction activities will be higher than those learned integrative communicative grammarthrough Group-5-Interaction activities." The Tukey test results for the paired group compared of $\mathrm{Q}_{5}$ (G3 and G5) shows that the probability ( $p$ ) level is 0.860 . As the probability is larger than $\alpha 0.05(0.860>0.05)$, the null hypothesis $\left(\mathrm{H}_{\mathrm{o}}\right)$ is accepted and can be concluded that the English proficiency of the students who learned grammar through Group-3-Interaction activities is not significantly higher than those learned grammar through Group5-Interaction activities. In other words, learning grammar for proficiency through Group-3-Interaction activities will not be more effective than learning it through Group-5-Interaction activities.

Hypothesis 10 assumed $\mathrm{H}_{\mathrm{a}}$ which stated that, "The English proficiency of the students who learned integrative communicative grammar through Group-4-Interaction activities will be higher than those learned integrative communicative grammarthrough Group-5-Interaction activities." The Tukey test results for the paired group compared of $\mathrm{Q}_{6}$ (G4 and G5) shows that the probability ( $\left.p\right)$ level is 0.928 . As the probability is larger than $\alpha 0.05(0.928>0.05)$, the null hypothesis $\left(\mathrm{H}_{\mathrm{o}}\right)$ is accepted and can be concluded that the English proficiency of the students who learned grammar through Group-4-Interaction activities is not significantly higher than those learned grammar through Group5-Interaction activities. In other words, learning grammar for proficiency through Group-4-Interaction activities will not be more effective than learning it through Group-5-Interaction activities.

\section{DisCUSSION OF FINDINGS}

Analyzing the students' achievement in learning integrative communicative grammar for English proficiency in all language skills through communicative activities in four models of classroom interaction, Pair, Group-of-3, Group-of-4, Group-of-5, has revealed many facts as evidence supporting the concepts which was constructed earlier in this research. It was postulated that learning grammar through purposeful classroom interaction strategies, primarily Pair-Interaction 
activities would affect English proficiency to a large extent in all language skills (Yassi, 2009; Hanafiah, 2011; Baleghizadeh, 2010; Nunan, 2003; and McLeod et al, 2003) compared to Group-Interaction activities.

One of the basic research questions initializing the data analysis was whether there is a difference of English proficiency among the students who learned integrative communicative grammar through Pair-Interaction, Group-of-3 Interaction, Group-of-4 Interaction, and Group-of-5 Interaction. This is to compare the results of learning of the participants measured by mean score and Univariate ANOVA procedures. The calculation results give strong support for a positive answer to this key research question, especially to those involved in Pair-Interaction activities. It was proved that this model contributes to the improvement of the scores in the posttest significantly.

The significant difference found to exist throughout the communicative activities/lessons between their significant gains in proficiency after the treatment, as measured by posttests; and the scores for their initial levels of proficiency, as measured by pretests, was evidence of the improvement. As the gain scores in the posttest were quite large up to12.53 points for all the tests, the gains were also uniformly significant across the five types of test. This evidence supports the Hypothesis 1 that the English proficiency of the students who learned grammar through Pair-Interaction activities before and after the intervention is significantly different. The question is, what factors account for differences in gain scores of posttest and pretest in this group?

Firstly, the students in all levels of English proficiency had their basic ability to understand and express their ideas and thoughts in English which was, to some extent, however, proved to be minimal in the pretest. Having a good command in all areas of English was also believed as their genuine needs and they had a tendency to pursue lots of efforts to make it true. Thus, this basic capacity together with the integrative communicative grammar teaching, which presupposes students' interaction while learning, can be viewed as significant substances in their cognitive process of learning English that reflects the sociocultural theory proposed by the Russian psychologist Vygotsky (1978).

Secondly, the improvement of English fluency of the students who learned grammar in Pair-Interaction was mostly caused by the opportunity for student talking time in students to student interaction. Their productive practicing time was normally up to 40 minutes per session per individual. The minimum participant of conversation allowed them to try ideas and thought together in a very safe environment in which dyadic interaction happens. In foreign language context, paired-interaction activities is a valuable opportunity for students to practice the target language they are learning as identified. Since they are in peer-interaction, they feel that they have equal counterpart to share reciprocal ideas and experiences. Here, the role of the teacher was minimized to a large extent. Therefore, such situation was maintained to be well directed to optimal target language use. McLeod et al, $(2003,164)$ also asserts that interaction with the greatest opportunity to learn comes when working with pairs. Thus, the finding is realistic to some extent as pairs would benefit from the regular and intensity of individual productive or practicing time through a true human interaction.

Thirdly, the grammar materials were purposefully designed to be integrated within communicative activities to scaffold the development of the students interactive proficiency. This was achieved through mutual exchange, negotiation and co-construction. Therefore a wide range of complementary activities was added.The task-cycle consisted of the performance of the task, the observation of their partner during the performance, the feedback after the performance, and vice-versa. The students also needed a reason to communicate to each other. Hence, information-gap was designed to allow them to help each other to fill in the gap through interactions. Thus, by a well-designed learning materials, they had their scaffolders helping them find related ideas to develop their English proficiency through intensive social interactions.

The discussion of the finding above does not imply that the students who learned grammar through pair interaction activities have mastered all areas of proficiency. What can be proved and learned from such finding is that time intensity with regular practices, familiarity of well-designed grammar tasks for communication, and homogenous peers of interaction, will improve students' English proficiency to a large extent. In other words, the combination of students' genuine needs to learn grammar for English proficiency can be enhanced if integrative communicative grammar takes place properly or within a purposeful interaction.

For the other three kinds of interation, the results of descriptive and inferential statistics through Univariate ANOVA procedures did not give strong support for a positive answer to this key research question. Although the increase of the scores had been tracked from pretest to posttest, the mean difference was proved to be insignificant through the Tukey test result. As all the gain scores of the three groups (G3, G4 and G5) in the posttest were not large or ranged from 2.56 to 5.93 points for all the tests, the gains were also uniformly insignificant across the five types of test with some exceptions. This evidence did not support the Hypothesis 2, 3 and 4 stating that the English proficiency of the students who learned grammar through Group-Interaction (three variations) activities before and after the intervention is significantly different. The question is, what factors account the rejection of alternative hypothesis?

Firstly, the students' English proficiency was minimal as evidenced by the group's scores in the pretest. The scores in the posttest increased however, but it was not significant. It was assumed that the size of groups directly influences the amount of possible "talking time" each student has; that in groups of three (G3) student can talk for about a third of the time, a forth in groups of four (G4) and a fifth in groups of five (G5). This, in turn, affected their fluency and English proficiency. The increase of group size was assumed to decrease the talking time for every individualas one had to share their ideas and thought in English with more than one member. Such decrease consequently reduced the 
amount of language practice through social classroom interaction that in turn affected the degree of intensity, fluency and proficiency in using the language.

Secondly, although the groups were designed to make students learning the grammar through interactions, less talkative students might discourage other members as they participated less. It might happen because they were less confident, shy, nervous, embarrassed, tongue-tied, affraid of making a lot of mistakes, spoke in their native language and not in English, had less to say, or simply did not feel convenient to practice the language in such grouping or did not enjoy working together. Whatever the reason, the effects were reflected in the test results as influenced by some weaknesses of interaction in group three and above.

Thirdly, although the grammar materials were designed integratively within communicative activities for groups of three to five, it still did not show the effects to scaffold the development of the students English proficiency to a large extent. Some of them tended to focus on form intensively while others tended to focus on meaning or the use. It was quite rare to find that they were trying to negotiate for problem solving on both as some of them tended to discuss the form in Bahasa Indonesia as they were shy and reluctant to say them in English. While this could actually be achieved through mutual exchange, negotiation and co-construction, the individuals should have reduced their mental blocks before groups processing proceeded. Thus, although by well-designed learning materials of language given to the groups, if students rejected communication and did not take advantage of the opportunities given in group activities, the changes would not be tremendous.

The discussion of the finding above implies that for the Group-Interaction ( 3 - 5 members) activities to take positive effects in English proficiency, the grouping model should be firstly matched with the students' genuine preference of the model. Besides, they should also be encouraged to talk more through well-designed English materials in group interactions and trained social interaction or interpersonal skills to improve their confidence. There should also be a strategy to develop their awareness upon dual focus on form and meaning within discussions. Consequently, 'talking more' needs more practicing time. Therefore, it is clear that the efficacy of Pair Interaction model lies on the increasing of practicing time (Haines, 1995; Harmer, 2001; and Rixon, 2000) and the minimum psychological constraints of static pair as a result of their daily contact with the same person.

\section{CONCLUSiOnS AND SugGeSTiOnS}

The English proficiency of the students who learn grammar through Pair Interaction improves to a large extent and outweighs their peers in Small Groups Interaction. The result implies the needs of varied interaction models according to students' preference in learning integrative communicative grammar. Therefore, the use of Pair Interaction is highly recommended for the low proficient students to give them more time to practice communication by introducing them interpersonal skills in Pair Interaction activities.

\section{REFERENCES}

[1] Baleghizadeh, S. (2010). "The Effect of Pair Work on AWord-Building Task", ELT Journal,64 (4), pp.405-413.

[2] Bandura, A. (1977). Social Learning Theory. EnglewoodCliffs, N.J.: Prentice-Hall.

[3] Dardjowidjojo, S. (2000). "English Teaching in Indonesia", EA Journal, 18(1), pp. 22-23.

[4] Ellis, R.(2006). "Researching the Effects of Form-Focused Instruction on L2 Acquisition", In Bardovi-Harlig, K. and Dornyei, Z. (Eds.), Themes in SLA Research. AILA, 19, pp. 18-41. Amsterdam: John Benjamins.

[5] Haines, S. (1995). "For and Against: Pairwork", Modern English Teacher, 4 (1), pp. 55-58.

[6] Hanafiah, W. (2011). "A Model of English Grammar Teachig Through Learner-Learner Interaction in Pair Activities and Its Contribution to The Learner's English Proficiency”,Unpublished Dissertation, Post Graduate Program, Hasanuddin University.

[7] Harmer, J. (2001). The Practice of English Language Teaching. London: Longman.

[8] Hedge, T. (2000). Teaching and Learning in the Language Classroom. Oxford: Oxford University Press.

[9] Hinkel, E. and S. Fotos. (2002). "From Theory to Practice: ATeachers' View", In Hinkel, E. and Fotos, S. (Eds.), New Perspectives on Grammar Teachingin Second Language Classroom. Mahwah, NJ: Lawrence ErlbaumAssociates, pp. 1-12.

[10] Lado, Robert. (1998). Teaching English Across Cultures. An Introduction for Teachers of English to Speakers of Other Languages. Washinton, D. C. MacGraw-Hill, Inc.

[11] McLeod, J., Fisher, J., and Hoover, G. (2003). The Key Elements of Classroom Management: Managing Time and Space, Student Behavior, and Instructional Strategies. Virginia: Association for Supervision and Curriculum Development.

[12] Nunan, D. (2003). Practical English Language Teaching. New York: McGraw-Hill.

[13] Rixon, S. (2000). "Group Work”, in Byram M. (ed) Encyclopedia of Language Teaching and Learning, pp. 252-253, Routledge.

[14] Sadtono, E. (1992). “Kompetensi Komunikatif: Mau ke Mana?.” Dalam Muljanto Sumardi (Ed.) Berbagai Pendekatan dalam Pengajaran Bahasa dan Sastra. Jakarta: Pustaka Sinar Harapan. Pp. 71- 92.

[15] Setiono, S. (2004). "Interpretation-Based Approach toGrammar Teaching: New Directions in Theory and Practice", TEFLIN Journal, 16 (2),pp. $169-180$.

[16] Ur, P. (1996). A Course in Language Teaching. Cambridge: Cambridge University Press

[17] Vygotsky, L.S. (1978). Mind in Society: The Development of Higher Psychological Processes. Cambridge: MA: Harvard University Press.

[18] Watanabe, Y., and Swain, M. (2007). "Effects of Proficiency Differences and Patterns of Pair Interaction on Second Language Learning: Collaborative Dialogue between Adult ESL Learners. Language Teaching Research 11, pp. 121-142. 
[19] Yassi, A.H. (2009). "Model Pembelajaran Gramatika Bahasa Inggris yang Berbasis 'Paired Interaction' dalam Rangka Meningkatkan Kompetensi Bahasa Inggris Mahasiswa: Kajian Eksperimental”, Buletin Penelitian, September 2009,7 (2), pp. $27-41$.

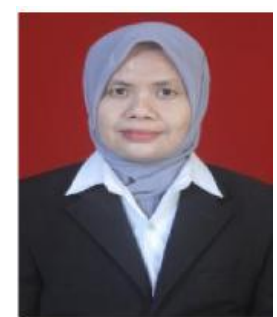

R, Suhartina, born on January $14^{\text {th }}, 1970$, has joined Doctorate Program at Hasanuddin University under the specialization of Linguistics Studies and finished in 2013. Started from 2008 to 2012, she was trusted as Dean of the Letter Faculty of Universitas Islam Indonesia. Since 2012 up to recent time she serves as English Lecturer of Kopertis wilayah IX Sulawesi under STIKIP-YAPIM Maros South Sulawesi Indonesia. She has carried out some researches mainly in teaching English Studies. 